\title{
Interferon-associated retinopathy in a patient with metastatic melanoma
}

\author{
Retinopatia relacionada ao interferon em paciente com melanoma metastático
}

\author{
Lara Borrego-Sanz ${ }^{1}$, Federico Sáenz-Francés ${ }^{1}$, M. Fernanda Fernández-Tresguerres ${ }^{1}$, Maria Jiménez-Santos ${ }^{1}$, Juan Donate-López ${ }^{1}$
}

\begin{abstract}
We present the unusual case of a 35 year-old woman with stage IV melanoma and widespread metastases, who was undergoing treatment with interferon alpha-2b and who presented with interferon-associated retinopathy. The patient, who had been taking interferon treatment for three months, complained of a sudden loss of visual acuity in the left eye. An ocular examination revealed multiple cotton wool spots along the retina and macular involvement. Interferon treatment was suspended. Although rare, retinopathy represents a potentially serious adverse effect of interferon treatment. Although normally patients are asymptomatic complications derived of its use may arise, which can lead to significant visua impairment. We therefore suggest that before initiating treatment with this drug, patients should be informed of its potential ocular risks, and that regular eye examinations are conducted along with the treatment.
\end{abstract}

Keywords: Interferon alfa/therapeutic use; Interferon alfa/adverse effects; Melanoma/secondary; Retinal diseases/chemically induced; Case reports

\section{RESUMO}

Apresentamos o caso de uma mulher de 35 anos com melanoma em estágio IV e metástases generalizadas tratados com interferon alpha-2b, que proporcionou uma retinopatia associada ao interferon. Mulher de 35 anos de idade tratados com interferon durante os últimos três meses apresentou uma perda súbita da acuidade visual no olho esquerdo. Exame ocular revelou vários pontos de algodão ao longo da retina e mácula. Tratamento com interferon foi parado. Retinopatia associada ao uso de interferon está entre os possíveis efeitos colaterais, embora rara, não deve ser subestimada. Embora geralmente assintomática, complicações decorrentes de seu uso podem levar à perda visual significativa. Consideramos, portanto, que antes de iniciar o tratamento com este medicamento, os pacientes devem ser informados sobre os riscos potenciais e os exames oftalmológicos são recomendados durante cada tratamento.

Descritores: Interferon-alfa/uso terapêutico; Interferon-alfa/efeitos adversos; Melanoma/secundário; Doenças retinianas/induzido quimicamente; Relatos de casos

\section{INTRODUCTION}

Interferons (IFNs) are a class of cytokine, some of which have the ability to inhibit cell proliferation and modulate viral replication functions of the immune system. They have wide clinical uses in multiple viral and tumorigenic processes, and have been classically used in the treatment of severe diseases such as hepatitis $C$ and multiple sclerosis. IFN is also the only accepted adjuvant treatment for patients with cutaneous melanoma ${ }^{(1)}$. Although generally well tolerated, incidences of IFN toxicity are commonly reported. The most common side effects are fever, myalgia, arthralgia, and headache. Retinal damage may also be associated with its use ${ }^{(2,3)}$. Furthermore, more serious disorders such as neurologic alterations, hepatotoxicity, and hematopoietic or cardiovascular irregularities, have been associated with IFN treatment ${ }^{(2,3)}$.

While IFN-associated retinopathy appears in 18-86\% of patients treated with the drug, (especially in patients suffering from hepatitis C, for whom IFN is widely administered), many of these cases are asymptomatic ${ }^{(4)}$. In a previous report describing patients with resected high-risk melanoma who received adjuvant IFN, 13\% developed retinopathy ${ }^{(5)}$

Since most of the adverse effects are due to toxicity, these symptoms usually resolve or improve after therapy discontinuation (1). Furthermore, there is a direct relationship between the dose and duration of treatment and the likelihood of retinopathy, with its appearance occurring between 8 and 12 weeks after the beginning of treatment ${ }^{(6)}$

However, in some cases complications that result in significant visual impairment can occur. Thus, monitoring and periodic ophthal- mologic evaluation of patients undergoing IFN treatment is highly recommended ${ }^{(1,2)}$. Here we report a case of atypical IFN-associated retinopathy involving macular changes, appearing in a young woman with cutaneous melanoma.

\section{CASE REPORT}

A 35 year-old woman presented with a history of spreading malignant melanoma of $1.1 \mathrm{~mm}$ Breslow thickness on her left arm. The melanoma was diagnosed in 2005. Four months ago, in a routine PET/CT extension study, metastases with bilateral axillary extensions were observed in both breasts. This required radical surgery, axillary lymphadenectomy, and radiotherapy. Oncogene mutation testing of BRAF V 600 E was positive. The patient was diagnosed with stage IV melanoma and was treated with IFN alpha-2b.

The patient received induction treatment of 33 million units (20 million units $/ \mathrm{m}^{2}$ ) of IFN al pha-2b intravenously, five days per week for four weeks. Subsequent maintenance therapy of 16 million units (10 million units $/ \mathrm{m}^{2}$ ) subcutaneously, three days per week, was initiated for a planned total of 11 months.

After three months of treatment, the patient came to our emergency room reporting visual loss and proptosis in the left eye for the previous two weeks, along with nausea and vomiting. The patients' ophthalmologic background comprised a strabismus surgery in childhood and later amblyopia of the right eye.

In the ensuing ophthalmologic examination, VA was 0.1 in the right eye and 0.4 in the left eye. A residual esotropia of $10^{\circ}$ in the right 
eye and a moderate proptosis in the left eye was detected, with extraocular and intraocular movements intact. The anterior segment and intraocular pressure appeared normal.

Fundus examination revealed multiple cotton wool spots along the vascular arcades and at the mid-peripheries of both eyes, in addition to peripapillary exudative lesions and mild venous tortuosity (Figure 1).

Fluorescein angiography (FA) was performed, which showed lack of perfusion areas by capillary closure coinciding with the cotton wool spots and pigmentary changes surrounding both foveas. An optical coherence tomography (OCT) examination of the macula revealed the presence of hard exudates in the outer plexiform layer of both eyes, and an epiretinal membrane (EM) in the left eye, possibly associated with exudative retinal microangiopathy secondary to the use of IFN (Figures 2 and 3).

It should be noted that our patient had no history of diabetes mellitus, arterial hypertension, or previous cardiovascular risk factors, all of which are known to be associated with the development and progression of retinopathy in patients undergoing IFN treatment $t^{(1,7,8)}$.

Nevertheless, given the patients' background, cerebral and orbital TC was requested, which revealed a retro-orbital mass of $15 \times 25 \mathrm{~mm}$ compatible with orbital metastases. The mass contacted the orbit floor, without producing erosion or hyperostosis. No brain disruptions were found (Figure 4).
Additional oncological examinations, including PET/CT, revealed new chest metastases. Given the retinal involvement and the advanced tumor progression, IFN treatment was stopped. The patient was included in an experimental clinical trial of Vemurafenib, a recently described drug that blocks the production of the protein kinase BRAF. At this point the patient discontinued her ophthalmologic examinations.

\section{DISCUSSION}

Although the pathogenesis of IFN-associated retinopathy remains unknown, it is believed to be caused by immune complex aggregations in ocular vessel walls. This is thought to increase leukocyte adhesion, which may trigger microcirculation obstruction ${ }^{(1-3)}$ Furthermore, it has been reported that IFN induces thrombogenic antibody proliferation ${ }^{(9)}$. Typical ocular complications associated with its use include ischemic retinopathy associated with cotton wool spots, retinal hemorrhages, and peripheral vascular obstructions ${ }^{(7,9)}$. Microaneurysms, neovascular glaucomas, and ischemic optic neuropathies have also been observed $(2,7,8)$.

Currently, IFN is the only accepted adjuvant treatment for patients with high-risk relapse melanoma ${ }^{(1)}$. We describe here a case of IFN-associated retinopathy in a patient with metastatic melanoma. This was diagnosed from several lines of evidence. Firstly, a fundus examination revealed the typical cotton wool spots associated with

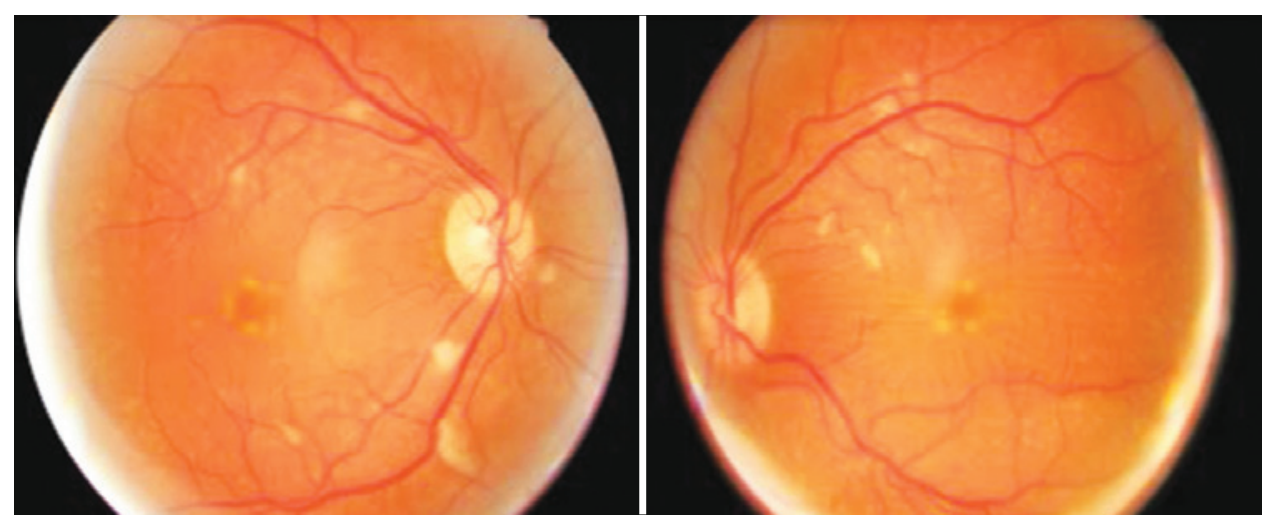

Figure 1. Fundus exam of the patient upon arrival in the emergency room following the use of interferon for three months. Cotton wool spots and peripapillary along the vascular arcades in both eyes can be observed.
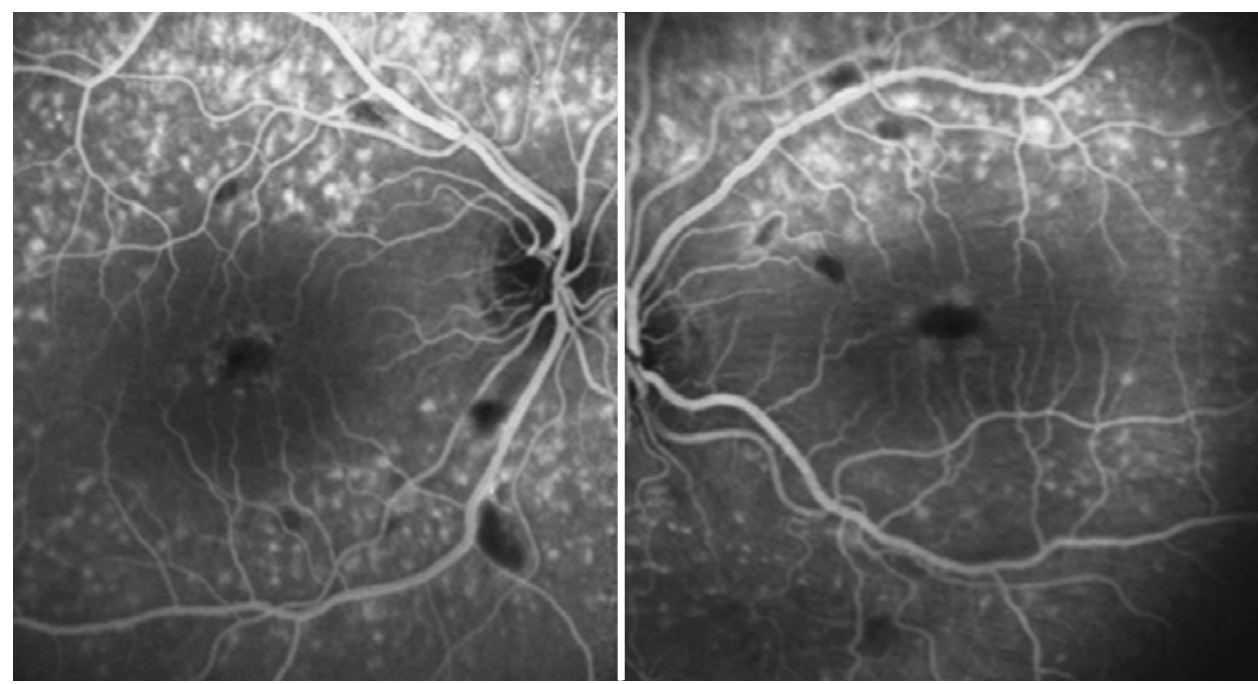

Figure 2. FA of the patient, where a lack of perfusion areas by capillary closure coinciding with cotton wool spots are shown. 

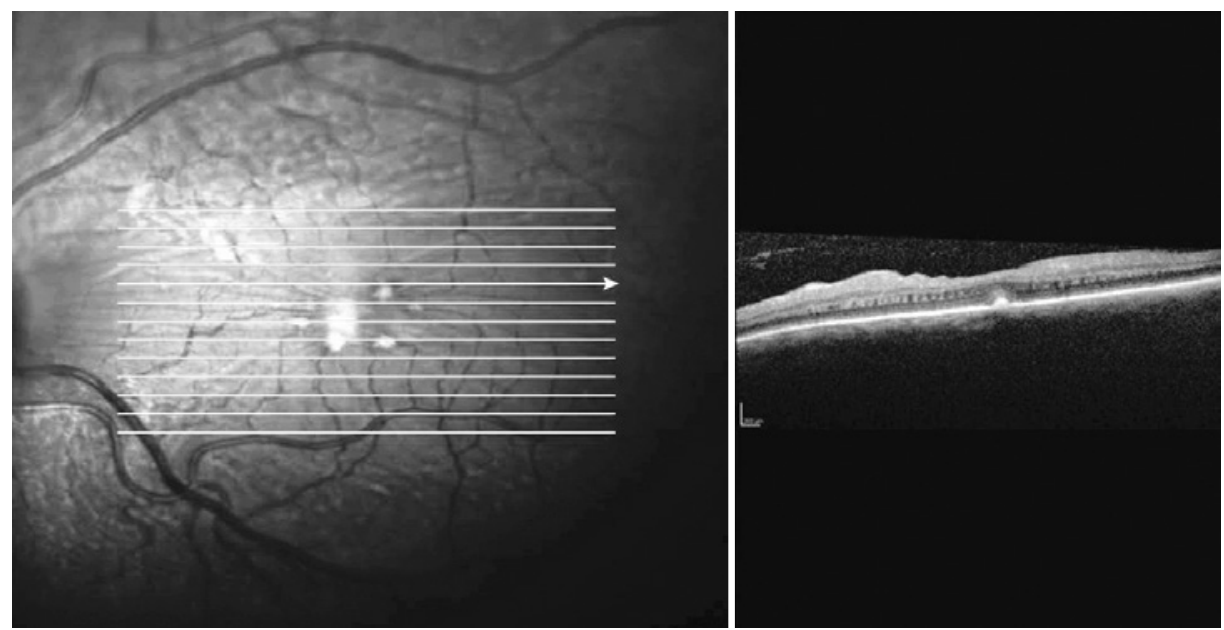

Figure 3. Macular OCT of the left eye, where hard exudates and an epiretinal membrane are observed, possibly related with the exudative retinal microangiopathy.

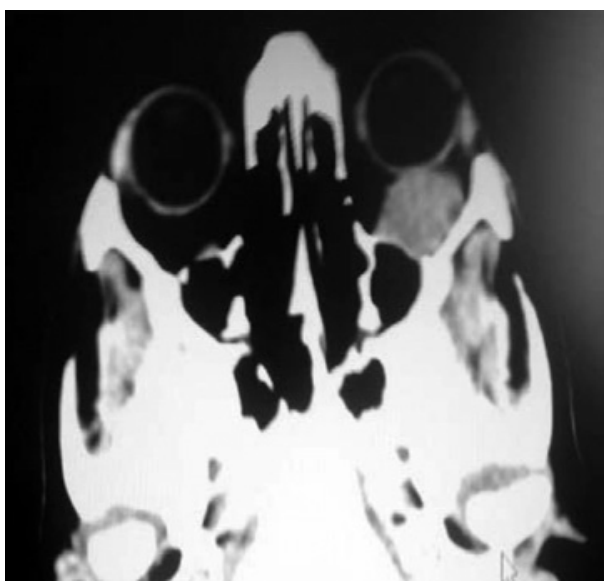

Figure 4. Left retroorbital metastasis displayed on the CT.

retinopathy. Also, symptoms appeared within three months following IFN intake, and the patient presented no comorbidities such as diabetes or hypertension, which could mask or aggravate the ocular findings. The bilateral nature of the findings are also suggestive of IFN-associated retinopathy, although the patient only realized visual loss in her dominant eye.

However, we suggest that a differential diagnosis should be considered for melanoma associated retinopathy (MAR) and radiation retinopathy. MAR is a rare autoimmune retinopathy that usually presents as night blindness and mild peripheral vision loss, with acuity and colour vision preserved. Substantial differences could differentiate both processes, since MAR is observed mainly in male patients and is usually not reversible with treatment discontinuation ${ }^{(1,10)}$. Radiation retinopathy might also be considered in the diagnosis, since it often shows clinical similarities. These include the vascular compromise on the posterior retina, which is normally more sensitive to radiation than the peripheral retina. Nevertheless, radiotherapy in our patient was administered long before IFN therapy and visual impairment was not previously reported ${ }^{(11)}$

It is possible that after discontinuation of IFN therapy most of the retinal lesions would have spontaneously disappeared, given the reversibility of IFN-associated side effects previously reported in multiple studies ${ }^{(1,2)}$. However, the prognosis of our patient was over- shadowed due to the advanced level of systemic tumor progression, that made it impossible to attend follow-up visits.

This case was also unusual because we detected some retinal changes not always observed in this kind of retinopathy. In particular, perimacular exudative damage that might be due to a transient period of choroidal hypoperfusion, appeared to have caused changes in the RPE. This may have formed an EM and thus resulted in long-term visual impairment. Choroidal vascular occlusion has also been described in patients under IFN therapy, but this usually occurs with associated comorbidities such as diabetes mellitus or hypertension ${ }^{(8,9)}$.

We note that the atypical features presented here occurred in a patient with no history of notable coexisting pathologies, and emphasise that in such cases vision-threatening complications might still occur. Therefore, it may be difficult to weigh the risk of continued IFN treatment against its undoubted benefits ${ }^{(8)}$. We therefore recommend that before initiating treatment, patients undergoing IFN therapy, should be informed of its potential ocular risks and, more importantly, they should be subjected to periodic ophthalmologic examinations.

\section{REFERENCES}

1. Monzon JG, Hammad N, Stevens S, Dancey J. Retinopathy associated with adjuvant high-dose interferon-a2b in a patient with resected melanoma: A case report and review of the literature. Oncologist. 2012;17(3):384-87.

2. Fragoso YD, Paggiaro MS, Mastromauro R, Jacondino Gda S, Wilson HM. Literature systematic review on the ophthalmological side effects of interferons. Arq Bras Oftalmol. 2011;74(4):306-10. Review. Erratum in: Arq Bras Oftalmol. 2012;75(2):148

3. Tu KL, Bowyer J, Schofield K, Harding S. Severe interferon associated retinopathy. $\mathrm{Br}$ J Ophthalmol. 2003:87(2):247-8.

4. Hayasaka S, Nagaki Y, Matsumoto M, Sato S. Interferon associated retinopathy. Br J Ophthalmol. 1998;82(3):323-5.

5. Sulkes A, Schachter J. Comment on "Perhaps not everyone knows that...", (Ann Oncol 2001;12:1186). Ann Oncol 2002;13:637.

6. Nagaoka T, Sato E, Takahashi A, Yokohama S, Yoshida A. Retinal circulatory changes associated with interferon-induced retinopathy in patients with hepatitis C. Invest Ophthalmol Vis Sci. 2007:48(1):368-75.

7. Burgueño-Montañés C, Pérez-Álvarez R. [Pegylated interferon and ribavirin associated retinopathy in patients with hepatitis C]. Arch Soc Esp Oftalmol. 2011;86(6):193-5. Spanish.

8. Mantel I, Konstantinidis L, Zografos L. Interferon-associated retinopathy. A case report. Klin Mombl Augenheilkd. 2007;224(4):350-2.

9. Bajaire B, Paipilla D, Arrieta C, Oudovitchenko E. Mixed Vascular Occlusion in a Patient with Interferon-Associated Retinopathy. Case Report Ophthalmol. 2011:2(1):23-9.

10. Audemard A, de Raucourt S, Miocque S, Comoz F, Giraud JM, Dreno B, Bienvenu B, Rogerie MJ, Dompmartin A. Melanoma-Associated Retinopathy Treated with Ipilimumab Therapy. Dermatology. 2013;227(2):146-9.

11. Gupta A, Dhawahir-Scala F, Smith A, Young L, Charles S. Radiation Retinopathy: Case report and review. BMC Ophthalmology. 2007:7:6. 